La Revue

des Droits

de l'Homme

\section{La Revue des droits de l'homme}

Revue du Centre de recherches et d'études sur les droits fondamentaux

Actualités Droits-Libertés | 2018

\title{
Un nouveau « Titre » à écrire...
}

A propos du titre de la nouvelle revue du Conseil constitutionnel

\section{Manon Altwegg-Boussac et Patricia Rrapi}

\section{OpenEdition}

\section{Journals}

Édition électronique

URL : http://journals.openedition.org/revdh/4817

DOI : $10.4000 /$ revdh.4817

ISSN : 2264-179X

\section{Éditeur}

Centre de recherches et d'études sur les droits fondamentaux

Référence électronique

Manon Altwegg-Boussac et Patricia Rrapi, « Un nouveau «Titre » à écrire... », La Revue des droits de I'homme [En ligne], Actualités Droits-Libertés, mis en ligne le 09 octobre 2018, consulté le 03 mai 2019. URL : http://journals.openedition.org/revdh/4817 ; DOI : 10.4000/revdh.4817

Ce document a été généré automatiquement le 3 mai 2019.

Tous droits réservés 


\title{
Un nouveau « Titre » à écrire...
}

\author{
A propos du titre de la nouvelle revue du Conseil constitutionnel \\ Manon Altwegg-Boussac et Patricia Rrapi
}

1 La revue du Conseil constitutionnel s'est donnée un nouveau titre : « Titre VII ». Des mots et chiffres ainsi prononcés ouvrent un temps de silence...Dont on ne sait pas tout de suite quoi en tirer.

2 Titre VII. A-t-on vraiment compris ? Certaines informations créent un doute sur sa propre lucidité : y a-t-il seulement quelque chose à comprendre ? Une subtile intention, une fine pensée, un bon mot, qui seraient accessibles aux seuls spécialistes. Outre ce petit effet sonore du « Titre VII » pour un titre de la revue, il y a sans doute autre chose à saisir. Mais à quoi bon tant de mystères pourrait-on s'étonner ? Car enfin, faut-il le rappeler, «Titre VII » c'est le Titre de la Constitution relatif au Conseil constitutionnel...Tout est dit. Certes.

3 Serait-ce un clin d'œil ? Celui de la créature à son créateur : le Conseil constitutionnel posant son regard sur le constituant lui dit « c'est moi que tu as façonné. Je suis le Conseil constitutionnel ». Après tout n'est-ce pas ce même Conseil qui « œuvre chaque jour pour que la Constitution demeure une norme solide mais aussi une norme vivante $»^{1}$. De là à intituler la nouvelle revue du Conseil tout simplement « Ma suprématie » ou « La Ve République », il s'en fallait de peu.

4 Serait-ce une brèche ? Opaque dans sa jurisprudence pourtant maîtrisée à merveille dans les commentaires officiels, l'institution décide «de mieux faire connaitre les différentes activités $d u$ Conseil constitutionnel » aux lecteurs du «Titre VII ». Un vœu de transparence donc pour se donner à voir... sous l'étendard d'un Titre pour l'autorité.

5 Serait-ce un aveu? Celui d'une Constitution absorbée dans le Titre VII. Mais lequel ? Celui de la Constitution ou celui de la Revue? Ainsi seraient résumés deux siècles de constitutionnalisme : la distinction du texte et de son interprétation par la doctrine, celle entre la Constitution et son gardien, celle entre le pouvoir constituant et les pouvoirs constitués. Il faudrait comprendre tout cela dans «Titre VII », la nouvelle revue du Conseil constitutionnel, et soigner ainsi la mémoire de Sieyès. 
Pourrait-il en être autrement ? Pourrait-il n'y avoir aucune intention? Il ne faut pas en douter...

Les Lettres « Actualités Droits-Libertés » (ADL) du CREDOF (pour s'y abonner) sont accessibles sur le site de la Revue des Droits de l'Homme (RevDH) - Contact

\section{NOTES}

1. Éditorial du Président Laurent Fabius pour le premier numéro de « Titre VII ».

2. Idem

\section{RÉSUMÉS}

La revue du Conseil constitutionnel s'est donnée un nouveau titre : «Titre VII ». Des mots et chiffres ainsi prononcés ouvrent un temps de silence...Dont on ne sait pas tout de suite quoi en tirer.

\section{AUTEURS}

\section{MANON ALTWEGG-BOUSSAC}

Professeur de droit public à l'Université Paris Est Créteil

PATRICIA RRAPI

Maître de conférences à l'Université Paris Nanterre 